\title{
Límites a la adaptación de jornada para la conciliación de la vida familiar (art. 34.8 ET).
}

\author{
Carmen Viqueira Pérez \\ Catedrática de Derecho del Trabajo y de la Seguridad Social. Universidad de Alicante
}

Resumen: La regulación del derecho a adaptar la jornada compele a la empresa a acoger la propuesta del trabajador o, en su defecto, a ofrecer alternativas a esa propuesta, admitiéndose la negativa de la empresa sólo en última instancia y sólo cuando ésta pueda legitimar su oposición en la existencia de una "razón objetiva". Acerca de la negativa empresarial gira la sentencia comentada.

Palabras clave: Jornada. Adaptación. Conciliación. Hijos. Cuidado.

Abstract: The regulation of the right to adapt the working time compels the company to accept the worker's proposal or, at least, to offer alternatives to that proposal, admitting the refusal of the company only as a last resort and only when it was possible to legitimize this opposition under the existence of an "objective reason." The commented sentence turns about that refusal of the worker's proposal.

Keywords: Working time. Adaptation. Conciliation. Children. Careful.

\section{Introducción}

En su versión vigente (de 2019), el art. 34.8 ET reconoce el trabajador, para conciliar su vida familiar con la prestación de trabajo, un derecho a la adaptación de jornada de contenido mucho más amplio que el que albergaba su versión original. Más amplio porque el trabajador puede adaptar su jornada de maneras muy variadas; más amplio, también, porque el derecho de adaptación -aunque ubicado como integrante del régimen jurídico de la jornada- desborda la jornada para alcanzar el modo en que la prestación se lleva a cabo (trabajo a distancia); y más amplio, en fin, porque la nueva dicción -más garantista que la anterior- compele a la empresa a acoger el régimen de ejercicio propuesto por el trabajador 0 , en su defecto, a ofrecer alternativas que permitan el disfrute del derecho, admitiendo la negativa de la empresa sólo en última instancia y sólo cuando pueda legitimar su oposición en la existencia de una "razón objetiva". En torno a la posibilidad de negativa empresarial gira la sentencia comentada que analiza, básicamente, dos frentes: el relativo a los efectos del incumplimiento del cauce procedimental establecido en el precepto y el que gira en torno a los requisitos que deba reunir la negativa empresarial.

\section{Identificación de la resolución judicial comentada}

Tipo de resolución judicial: sentencia.

Órgano judicial: Sala de lo Social. Tribunal Superior de Justicia de Aragón. Sala de lo Social. 
Número de resolución judicial y fecha: Sentencia núm. 13/2021, de 19 de enero.

Tipo y número recurso o procedimiento: Recurso de suplicación núm. 637/2020.

ECLI: ES:TSJAR:2021:41

Fuente: CENDOJ.

Ponente: Ilmo. Sr. D. José-Enrique Mora Mateo.

Votos Particulares: carece.

\section{Problema suscitado. Hechos y antecedentes}

El litigio que la sentencia analiza y resuelve gira en torno a la negativa de la empresa (DECATHLON) a adaptar la jornada de una trabajadora al amparo del art. 34.8 ET.

La trabajadora viene prestando servicios como vendedora en la sección de Fitness de la tienda que la empresa DECATHLON tiene en Huesca desde que -en 2011- se incorporó a su plantilla al amparo de un contrato a tiempo parcial por el que comenzó a prestar trabajo de lunes a domingo a razón de 16 horas semanales. Cuatro años después de ingresar en la empresa (noviembre de 2015) las partes acordaron la novación del contrato que se convirtió en un contrato a tiempo completo con jornada de mañana y tarde y horario flexible.

Tras un año de prestar trabajo a jornada completa, la trabajadora (en diciembre de 2016) solicitó reducir su jornada a 35 horas semanales. La empresa aceptó la propuesta y en este nuevo régimen de jornada reducida comenzó a prestar trabajo en distintas franjas horarias (parece que de mañana y tarde), si bien consta que la empresa ha atendido las puntuales peticiones de la trabajadora -madre de dos hijos menores de 12 años- para poder conciliar la prestación de trabajo con su vida familiar.

Tres años después -en febrero 2020- la trabajadora solicita concretar su jornada de trabajo fijándola en la franja de 9.30 a 16:30 cualquier día de la semana, petición a la que la empresa, sin sustanciar negociación alguna ni efectuar propuesta alternativa, se niega aduciendo necesidades organizativas en la sección en la que trabaja (Fitness) ya que la mayor afluencia de clientes tiene lugar los sábados por la tarde a partir de las 16:30. En instancia, la trabajadora obtiene el reconocimiento del derecho a adaptar su jornada en los términos propuestos y a percibir una indemnización por daños y perjuicios que se cifra en 1.500 euros (una cuantía inferior a la solicitada por la trabajadora).

\section{Posición de las partes}

Para conciliar su vida familiar con el desarrollo de su trabajo, la trabajadora -madre de dos niños menores de 12 años- pretende adaptar su jornada de trabajo de modo que la prestación de las 35 horas que realiza cada semana se lleve a cabo en la franja de 9:30 a 16:30 cualquier día de la semana. La propuesta (según se deduce de los hechos probados) se formula sin más detalle, de modo que parece dejarse a una posterior concreción los días en que se va a prestar trabajo, así como la duración de la jornada diaria y su horario.

La empresa, por su parte, después de significar en su comunicación que ha venido realizando un esfuerzo en la planificación para que la trabajadora pudiera atender sus necesidades de conciliación, se niega a implementar la adaptación de jornada que la trabajadora pretende alegando que no le es posible concretar ese horario de forma sostenida debido a las necesidades organizativas de la sección de Fitness (en la que la trabajadora presta servicios como dependienta) porque los sábados, a partir de las 16:30, esa sección experimenta la mayor afluencia de clientes. 


\section{Normativa aplicable al caso}

La normativa aplicable al caso es, en esencia, el art. 34.8 ET: "Las personas trabajadoras tienen derecho a solicitar las adaptaciones de la duración y distribución de la jornada de trabajo, en la ordenación del tiempo de trabajo y en la forma de prestación, incluida la prestación de su trabajo a distancia, para hacer efectivo su derecho a la conciliación de la vida familiar y laboral.

Dichas adaptaciones deberán ser razonables y proporcionadas en relación con las necesidades de la persona trabajadora y con las necesidades organizativas $o$ productivas de la empresa.

En la negociación colectiva se pactarán los términos de su ejercicio, que se acomodarán a criterios y sistemas que garanticen la ausencia de discriminación, tanto directa como indirecta, entre personas trabajadoras de uno y otro sexo. En su ausencia, la empresa, ante la solicitud de adaptación de jornada, abrirá un proceso de negociación con la persona trabajadora durante un periodo máximo de treinta días. Finalizado el mismo, la empresa, por escrito, comunicará la aceptación de la petición, planteará una propuesta alternativa que posibilite las necesidades de conciliación de la persona trabajadora o bien manifestará la negativa a su ejercicio. En este último caso, se indicarán las razones objetivas en las que se sustenta la decisión".

También sirven al análisis que la sentencia lleva a cabo los art. 38 y 39 CE que contienen los derechos constitucionales interesados en el conflicto (protección de la familia, maternidad y filiación; y libertad de empresa) y el art. 14 CE por cuanto el ejercicio de las responsabilidades parentales ha de hacerse -como ya ha señalado el TC- en términos coherentes con el principio de igualdad y la interdicción de discriminación por razón de sexo.

Art. 38 CE: "Se reconoce la libertad de empresa en el marco de la economía de mercado. Los poderes públicos garantizan y protegen su ejercicio y la defensa de la productividad, de acuerdo con las exigencias de la economía general y, en su caso, de la planificación".

Art. 39 CE: "1. Los poderes públicos aseguran la protección social, económica y jurídica de la familia. 2. Los poderes públicos aseguran, asimismo, la protección integral de los hijos, iguales éstos ante la ley con independencia de su filiación, y de las madres, cualquiera que sea su estado civil. La ley posibilitará la investigación de la paternidad. 3. Los padres deben prestar asistencia de todo orden a los hijos habidos dentro o fuera del matrimonio, durante su minoría de edad y en los demás casos en que legalmente proceda. 4. Los niños gozarán de la protección prevista en los acuerdos internacionales que velan por sus derechos".

Art. $14 \mathrm{CE}$ : "Los españoles son iguales ante la ley, sin que pueda prevalecer discriminación alguna por razón de nacimiento, raza, sexo, religión, opinión o cualquier otra condición o circunstancia personal o social".

Aunque sólo traído a colación para contextualizar el art. 34.8 ET, la sentencia baraja también el art. 9 de la Directiva 2019/1158 relativa a la conciliación de la vida familiar y la vida profesional de los progenitores y los cuidadores: "Los empleadores estudiarán y atenderán las solicitudes de acogerse a fórmulas de trabajo flexible a que hace referencia el apartado 1 en un plazo razonable de tiempo, teniendo en cuenta tanto sus propias necesidades como las de los trabajadores. Los empleadores deberán justificar cualquier denegación de estas solicitudes, así como cualquier aplazamiento de dichas fórmulas".

\section{Parte dispositiva}

La sentencia comentada desestima el recurso de suplicación interpuesto por la empresa frente a la sentencia del Juzgado de lo Social de Huesca de 8 de octubre de 2020 que reconoció a la trabajadora el derecho a adaptar la jornada en los términos propuestos (fijándolo en la franja de 9:30 a 16:30) y el derecho a percibir una 
indemnización de 1.500 euros por el daño moral derivado de los perjuicios ocasionados por la negativa de la empresa, que no negoció con la trabajadora ni presentó alternativa alguna a los términos de disfrute propuestos por aquella.

Así, la sentencia afirma que "en conclusión, la adaptación solicitada resulta razonable y proporcionada en relación con las necesidades de la persona trabajadora, y la negativa de la empresa no ha sido razonablemente justificada en sus necesidades organizativas o productivas".

La actuación de la empresa infringe lo establecido en el art. 34.8 ET: "Se ha producido por lo tanto la infracción, declarada en la sentencia de instancia, del art. 34.8 del Estatuto de los Trabajadores por parte de la empresa demandada, al no haber llevado a cabo el período de negociación establecido en el mismo y no haber acreditado las razones organizativas o productivas que justificaran su negativa a la concreción horaria interesada por la demandante".

Y de esa infracción del art. 34.8 ET deviene el derecho a obtener una indemnización por daños morales para la que no es preciso que exista "una discriminación $u$ otro derecho fundamental infringido" porque "es innegable la producción de perjuicios a la trabajadora por una negativa de la empresa que, se insiste, se produjo sin la previa negociación y presentación de alternativas que exige la ley".

\section{Pasajes decisivos}

El hilo argumental de la sentencia tiene como punto de partida el papel central que -en los derechos de conciliación de la vida familiar y laboral- cumple el derecho de adaptación contenido en el art. 34.8 ET al que el legislador, consciente de su transcendencia, dota de todo un armazón procedimental -periodo de negociación, ofrecimiento de alternativas- que la empresa infringe (a). La exigencia de que se produzca un periodo negociador entre la empresa y el trabajador en el que ambos deben aportar sus propuestas y alternativas no impide que la empresa pueda oponerse a la propuesta de adaptación formulada por la trabajadora, siempre y cuando la negativa empresarial responda a justificadas razones objetivas que, en este caso, no concurren (b). De ahí que la injustificada negativa de la empresa y la también dilación en el disfrute del derecho que inevitablemente conlleva, originen un perjuicio a la trabajadora del que deviene su derecho a reclamar una indemnización por daños y perjuicios (c).

(a) La sentencia es particularmente prolija en la exposición del sentido que ha de atribuirse al art. $34.8 \mathrm{ET}$ que, en su vigente redacción, reconoce a favor del trabajador un verdadero derecho a adaptar su prestación de trabajo para hacerla compatible con su vida familiar: "El núcleo principal de la reforma descansa en la concepción de la adaptación de jornada como un derecho del trabajador, a diferencia de la necesidad de acuerdo que sentaba la norma anterior".

A este derecho de adaptación sirven las exigencias procedimentales que el precepto contiene y cuya importancia la sentencia señala reiteradamente. En este sentido, se afirma que "Del contenido del art. 34.8 del ET, resalta, además de su concepción como un derecho de la persona trabajadora (...) la importancia de que se produzca un proceso negociador entre empresa y trabajador, y que la negociación sea efectiva, proponiéndose alternativas (...) (de) que las partes se esfuercen en justificar los motivos que fundamentan su posición, asi como los perjuicios que padecerían si no se aceptara su propuesta; (de) que las alternativas sean motivadas, en el sentido de razonables y satisfactorias; (y de) que la eventual negativa de la empresa sea igualmente motivada, en el sentido de objetivamente razonada."

Dado que "no consta negociación alguna tras la petición de la trabajadora", limitándose la empresa a comunicarle mediante carta que "no es posible concretar su horario de forma sostenida de manera continuada, por ser un horario fuera de su jornada ordinaria (...) que se ha venido realizando un esfuerzo en la planificación para facilitar el horario flexible fuera de la jornada ordinaria (y que) en atención tanto a las 
necesidades organizativas de la sección en la que trabaja la demandante, como por la jornada ordinaria que viene realizando", ha de concluirse que "se ha producido por lo tanto la infracción, declarada en la sentencia de instancia, del art. 34.8 del Estatuto de los Trabajadores por parte de la empresa demandada, al no haber llevado a cabo el período de negociación establecido en el mismo".

(b) Acerca de la causa objetiva que sustenta la negativa empresarial, la sentencia mantiene su insuficiencia. Se parte de la base de que "como apunta la doctrina, (Casas Baamonde) "debe exigirse una ponderación de los derechos fundamentales en conflicto y encontrar criterios practicables que permitan la conciliación de las medidas de compatibilidad de la vida familiar y laboral de los trabajadores y las necesidades empresariales, atendiendo a la dimensión constitucional de los derechos de conciliación y evitando su restricción injustificada y desproporcional", pero en este caso "la trabajadora acredita una situación objetiva de necesidad de conciliación, dadas las características del horario de trabajo del cónyuge, y la empresa no ha demostrado que a su petición se opongan objetivas y razonables necesidades organizativas o productivas, pues no lo es la única esgrimida de que las tardes de los sábados sean los momentos de mayor afluencia de clientes, puesto que frente a este hecho debería haber razonado y probado la empresa la imposibilidad de cubrir su puesto esas tardes con otro personal de la plantilla. Además consta que en la sección de la trabajadora hay 7 personas adscritas y ninguna de ellas tiene adaptación de jornada vigente. En conclusión, la adaptación solicitada resulta razonable y proporcionada en relación con las necesidades de la persona trabajadora, y la negativa de la empresa no ha sido razonablemente justificada en sus necesidades organizativas o productivas".

La sentencia, por lo demás, a la hora de valorar "las necesidades de la persona trabajadora", otorga una muy discutible (a mi juicio) transcendencia a la posibilidad de que el cónyuge se vea impedido para hacerse cargo de la "tarea" de conciliación, habida cuenta de la irregularidad de su horario de trabajo (turnos de mañana, tarde y noche). Así, se señala en varios pasajes que "su cónyuge trabaja como Guardia civil en turnos no fijos ni uniformes" y este dato se parece tener un peso esencial a la hora de valorar la razonabilidad de la adaptación solicitada por la trabajadora al afirmarse que "la trabajadora acredita una situación objetiva de necesidad de conciliación, dadas las características del horario de trabajo del cónyuge".

(c) Por lo que hace a la indemnización por daños morales, la sentencia afirma que su reconocimiento no exige la existencia de discriminación o vulneración de otros derechos fundamentales puesto que la negativa infundada de la empresa genera a la trabajadora perjuicios que merecen reparación "Finalmente la empresa se opone a que exista una discriminación u otro derecho fundamental infringido que pudiera motivar la indemnización por daños morales declarada. No cita en apoyo de su argumentación precepto legal ni jurisprudencia alguna infringida (no lo es en esta materia una Sentencia de Tribunal Superior, no del Tribunal Supremo), lo cual basta, en este recurso extraordinario de suplicación, para la desestimación de su petición, además de que la condena al respecto contenida en la sentencia recurrida está ajustada a parámetros objetivos legales y precedentes decisiones en casos análogos, que en la misma se indican, y es innegable la producción de perjuicios a la trabajadora por una negativa de la empresa que, se insiste, se produjo sin la previa negociación y presentación de alternativas que exige la ley"

\section{Comentario}

Como se sabe, en su versión actual, el art. 34.8 ET reconoce el trabajador, para conciliar su vida familiar con la prestación de trabajo, un derecho a la adaptación de jornada de contenido mucho más amplio que el que albergaba su versión original. Más amplio porque el trabajador puede adaptar su jornada de maneras muy variadas; más amplio, también, porque el derecho de adaptación desborda la posibilidad de redefinir la jornada para alcanzar el modo en que la prestación se lleva a cabo (trabajo a distancia); y más amplio, en fin, porque la nueva dicción -más garantista- compele a la empresa a acoger el régimen de disfrute propuesto por el trabajador o, en su defecto, 
a ofrecer alternativas al régimen propuesto, admitiéndose sólo en última instancia la negativa de la empresa y sólo cuando esta pueda legitimar su actuación en la existencia de una "razón objetiva". En torno a la posibilidad de negativa empresarial gira la sentencia comentada que analiza, básicamente, dos frentes: el relativo a los efectos del incumplimiento procedimental (a) y el que gira en torno a los requisitos que deba reunir la negativa empresarial (b).

(a) La sentencia entiende que la empresa no ha llevado a cabo el proceso negociador requerido por el art. 34.8 ET y mantiene -aunque con escasa argumentación- que esa infracción inevitablemente condena al fracaso la pretensión de la empresa, conclusión que -a mi juicio- no cabe sino compartir. En efecto, como se sabe, en ausencia de reglas convencionales que ordenen el ejercicio del derecho de adaptación, establece el art. 34.8 ET que, ante la solicitud del trabajador, la empresa debe abrir un proceso de negociación -durante un periodo máximo de treinta días- a cuya finalización, comunicará por escrito la aceptación de la petición, planteará una propuesta alternativa que posibilite las necesidades de conciliación de la persona trabajadora o bien manifestará la negativa a su ejercicio, debiendo, en este último caso, indicar las razones objetivas en las que se sustenta su decisión. De modo que el precepto, si bien se mira, impone a la empresa un deber de negociar que, obviamente, no implica el deber de llegar a un acuerdo (por cuanto que la empresa puede aceptar, ofrecer una alternativa o negarse a la propuesta del trabajador), pero sí exige el despliegue de una cierta actividad demostrativa de la voluntad de llegar a él.

Por eso, para cumplir el fin pretendido en el precepto no basta el simple transcurrir del tiempo porque ello únicamente conduce a un vaciamiento del verdadero deber impuesto a las partes, que es el de negociar, el de intentar acercar sus posiciones y encontrar un cauce para hacer posible el ejercicio del derecho del trabajador y la preservación de los legítimos intereses productivos de la empresa. Desde otra perspectiva, podría decirse que, para oponerse al ejercicio del derecho de adaptación pretendido por el trabajador, a la empresa no le basta tener una razón organizativa suficiente y comunicarla, sino que habrá de exponer estas razones en el proceso negociador, ofrecer alternativas que permitan el disfrute del derecho -si ello es posibley/o negarse a su ejercicio en los términos propuestos si no se encuentra el modo de armonizar el derecho del trabajador con las razones objetivas de la empresa.

(b) Por otro lado, no toda "razón objetiva" aducida por la empresa resulta suficiente para fundamentar la legítima negativa a la propuesta efectuada por el trabajador. Esta insuficiencia (que ha de ser medida en cada caso) es lo que aprecia la sentencia comentada que, con acierto, entiende que a la solicitud de una vendedora de la sección de Fitness de fijar su jornada en la franja de 9:30 a 16:30 no puede oponerse la negativa de la empresa aduciendo que el sábado por la tarde se produce la mayor afluencia de clientes en esa sección.

Como se sabe, el derecho de adaptación se encuentra sometido a un doble límite: que las medidas propuestas por el trabajador sean "razonables y proporcionadas en relación con las necesidades de la persona trabajadora y con las necesidades organizativas o productivas de la empresa" y que sólo la concurrencia de "razones objetivas" resulte ser válida para legitimar la negativa de la empresa a aceptar esa adaptación "razonable y proporcionada" propuesta por el trabajador.

Con respecto al primero de ellos, es pacífica la idea de que la propuesta de adaptación formulada por el trabajador ha de tener en cuenta las necesidades de conciliación, las necesidades organizativas de la empresa y los derechos del resto de trabajadores. Lo que resulta muy dudoso, en mi opinión, es que para evaluar si existe esa "necesidad de conciliación" además de considerar la necesidad de conciliación "propia" (del titular del derecho) haya de demostrarse la imposibilidad de que concilie la pareja (o incluso otro familiar -como puedan ser los abuelos- o un cuidador). Esta es la idea que mantiene la sentencia que, para afianzar el derecho de la trabajadora, apunta a la imposibilidad de que su pareja concilie señalando que "su cónyuge trabaja como Guardia civil en turnos no fijos ni uniformes", y que la trabajadora acredita "una situación objetiva de necesidad de conciliación, dadas las características del horario 
de trabajo del cónyuge", afirmaciones que conducen a pensar que, de haber tenido el marido un horario regular y uniforme, el derecho de la trabajadora podría haber resultado perjudicado.

No comparto esta interpretación. En mi opinión, es más acertado mantener que el titular del derecho de adaptación no está obligado a demostrar la imposibilidad de que concilie su cónyuge (u otro familiar) porque el derecho de adaptación se configura en el art. 34.8 ET como un derecho de titularidad individual cuyo ejercicio no se condiciona a la existencia de una suerte de "necesidad insuperable de conciliar" derivada de la imposibilidad de atender la conciliación a través de otras medidas y/o con ayuda de otras personas. El derecho de adaptación depende, únicamente, de la existencia de los presupuestos objetivos que dan derecho a conciliar: tener hijos o familiares a los que cuidar y verse imposibilitado para hacerlo manteniendo el régimen de prestación de trabajo. En este sentido se manifiesta la reciente STSJPV de 20 de octubre de 2020 (Rec. 1157/2020) que señala que "es un derecho individual a ejercer por la trabajadora (...) siempre y cuando cumpla los requisitos establecidos legalmente".

Partiendo de esta base, el derecho no puede entenderse sujeto a la demostración de que otras personas no puedan hacerse cargo de esa tarea de cuidado, de modo que bastará con evidenciar la necesidad de conciliación "propia"; esto es, la necesidad del titular del derecho de adaptar la jornada para poder conciliar (quedando extramuros del derecho sólo aquellas adaptaciones de jornada caprichosas en el sentido de no necesarias para conciliar -puede verse un ejemplo en la STSJ de Cataluña de 17 de julio de 2018-, o inútiles al cumplimiento de su objetivo -JS Gijón 29 agosto 2019-). Por esta razón -y con mayor motivo- tampoco creo que el juez esté facultado para determinar quién de los dos progenitores debe conciliar en aras a fomentar la corresponsabilidad (sobre ello, con muy sólida argumentación las STSJ Galicia 22 de julio de 2019 y 28 de mayo de 2019). Conclusión de todo ello es que "la presencia o no de terceros que a su vez pudieran también intervenir en el cuidado del familiar afectado, incluso directamente, no altera el ejercicio de tal derecho. No solo por el carácter individual del mismo (...) sino porque tal cuidado puede adquirir modos diversos en lo que a su práctica diaria" (STSJPV de 20 de octubre de 2020 -Rec. $1157 / 2020-)$

A esa propuesta razonable y proporcionada que debe hacer el trabajador puede oponerse la empresa alegando razones objetivas que, de modo pacífico, se identifican con la concurrencia de causas organizativas o productivas (con la protección, en fin, de la libertad de empresa y el derecho a establecer una organización acorde con los intereses empresariales) que, como es lógico pensar, han de revestir la entidad suficiente para poder obstaculizar el derecho de adaptación. La sentencia parte de esta base y concluye que la razón objetiva ofrecida por la empresa no es suficiente para oponerse al ejercicio del derecho porque el hecho de que la sección en la que presta servicios la trabajadora -Fitness- acumule la mayor afluencia de clientes las tardes de los sábados, no justifica de suyo la necesidad de que la trabajadora preste trabajo en esa franja horaria, toda vez que la empresa cuenta con 7 personas adscritas a esa sección que no disfrutan de adaptación de jornada por conciliación y que bien podrían cubrir las necesidades de la tarde del sábado.

Para poder oponerse a la adaptación solicitada por la trabajadora -como señala claramente la sentencia- no basta que la empresa alegue una mayor afluencia de clientes los sábados por la tarde sino que la empresa debería haber "razonado y probado" la imposibilidad de cubrir el puesto de la trabajadora con otro personal de la plantilla; extremo que, por lo demás, la empresa podía haber resuelto sin gran dificultad, desplegando una mínima actividad argumentativa y probatoria acerca del número de clientes que acuden los sábados por la tarde; de la importancia (en número y cuantía) de las ventas que se realizan esa tarde en relación con las producidas otros días de la semana; de la insuficiencia de trabajadores para poder atenderlas...). Como viene señalando la doctrina judicial, al empresario le corresponde demostrar que concurren razones poderosas -normalmente organizativas- que le impiden aceptar el 
disfrute del derecho en los términos planteados por el trabajador, de modo que no resulta suficiente alegar razones organizativas de carácter genérico sino que la empresa debe indicar, de forma concreta, la imposibilidad o la importante dificultad de aceptar la propuesta de disfrute efectuada por el titular del derecho (en este sentido, entre otras, STSJ Andalucía 3 mayo 2018 -Rec. 979/2018- y STSJ Galicia 20 noviembre 2017 -Rec.3626/2017-).

\section{Apunte final}

Es un lugar común señalar que la reforma de 2019 amplió de manera sustancial el alcance del derecho a la adaptación de la jornada para la conciliación de la vida familiar y laboral, evidenciando así el legislador la voluntad de fortalecer las herramientas que permitan la conciliación. Pero, como es lógico, el derecho de adaptación está sometido a ciertas limitaciones en las que el legislador demuestra que es también consciente de la necesidad de sujetar el ejercicio del derecho a la ponderación de los intereses en conflicto (los del titular del derecho de adaptación, las necesidades organizativas de la empresa y los derechos del resto de trabajadores). Por eso, las medidas propuestas por el trabajador han de ser "razonables $y$ proporcionadas en relación con las necesidades de la persona trabajadora y con las necesidades organizativas o productivas de la empresa" y por eso sólo la concurrencia de "razones objetivas" puede legitimar la negativa de la empresa.

La aplicación práctica de estos límites no es siempre sencilla y la doctrina judicial muestra posiciones dispares en cuestiones de tanta importancia que, habida cuenta de la dificultad para que se produzca unificación de doctrina en esta materia- fácilmente justificarían una intervención normativa para su clarificación. En este sentido, no estaría de más determinar que la "necesidad de conciliación" debe identificarse con la necesidad de conciliación "propia" (del titular del derecho) y no exige demostrar la imposibilidad de que concilie la pareja (o incluso otro familiar o un cuidador); y también debería clarificarse que, para legitimar la negativa de la empresa, no basta alegar razones organizativas de carácter genérico sino que resulta preciso evidenciar (léase argumentar y probar) la imposibilidad de aceptar la propuesta de disfrute efectuada por el titular del derecho. 